\title{
Exploring novel solutions for incorporating vacuum glazing in new and existing window constructions
}

\author{
Ulrich Pont ${ }^{1, *}$, Magdalena Wöltzl $^{1}$, Matthias Schuss ${ }^{1}$, Peter Schober $^{2}$, Ardeshir Mahdavi $^{1}$ \\ ${ }^{1}$ Department of Building Physics and Building Ecology, TU Wien, Vienna, Austria \\ ${ }^{2}$ Holzforschung Austria, Vienna, Austria
}

\begin{abstract}
This contribution discusses recent progress in development of windows equipped with vacuum glass. Vacuum glazing is commonly understood as glass products consisting of two parallel glass panes with a very narrow gap. Moreover, they feature a tight edge seal and house a grid of distance pillars. During production the gap is evacuated. As a result, vacuum glazing products widely eliminate convective heat transfer and minimize conductive heat transfer. As such, they represent highly-insulating glass products that regularly feature U-values in the range of triple-glazing, or even below (about 0.2 to $0.3 \mathrm{~W} \cdot \mathrm{m}^{-2} \cdot \mathrm{K}^{-1}$ ). While the research pertaining to the development of vacuum glass can be traced back to the first patent of 1913 [1], relatively few research efforts have been conducted regarding the application of vacuum glazing in window constructions. In this context, the present contribution focuses on the application of vacuum glass products in window constructions. Toward this end, two application cases are addressed in detail. One effort addresses the application of vacuum glass in new window constructions. The major objective of this effort is the reduction of heat flow through the window construction. Thereby, innovative paradigms involving multiple operation, size, and construction options are considered. The second case deal with the potential of vacuum glazing products in view of deployment in thermal retrofit of existing buildings. This application case does not only focus on the thermal performance of the windows, but also on the necessity to protect the appearance of heritage building facades (including those of the historical window constructions). As such, vacuum glazing products provide an alternative to replacing existing windows with high-insulating triple-glazed products.
\end{abstract}

\section{Introduction}

The A-E-C domain is confronted with huge challenges, given the ongoing environmental debate about emissions and energy consumption of buildings. Thereby, transparent building envelope components are considered to be responsible for a major share of heat losses and thus for a major portion of energy consumption and related emissions. As such, there is an urgent need to improve the thermal performance of transparent building envelope components. Past improvements included the introduction of double and triple glazing, the implementation of low-e treatment, and the design of specific edge compound materials. However, the way in which windows and facades have been constructed in the past decades cannot be said to have undergone significant changes. Moreover, the mentioned technologies may be converging on their limits. Research and development in the area of evacuated glass panes has been ongoing since many decades. In the past years, different vacuum glass products emerged on the market that seem to have widely solved the issues of durability. While many research efforts pertaining to the development of such glass products are documented, surprisingly few efforts address the implementation of vacuum glass panes into window and façade constructions. However, such research efforts are required to address the implementation of vacuum glass panes into the daily planning routine of facades and windows. Recent and past research efforts conducted by the authors addressed the following research questions:

1. How can vacuum glass products be used for the thermal enhancement of existing, historically relevant window constructions such as casement windows?

2. How should windows be designed that accommodate the specifics of vacuum glass products?

3. How do vacuum glass products affect the performance of typical post-and-beam façade constructions if used as supplement or complement to regular insulation glass?

Figure 1 illustrates the constituent elements of typical vacuum glass products (Glass edge seal, distance pillars), as well as the relevant terminology for assessment of the thermal performance of vacuum glass (Glass seal width, pillar distance, and glass edge cover length).

\footnotetext{
* Corresponding authors: ulrich.pont@tuwien.ac.at and magdalena.woelzl@tuwien.ac.at
} 


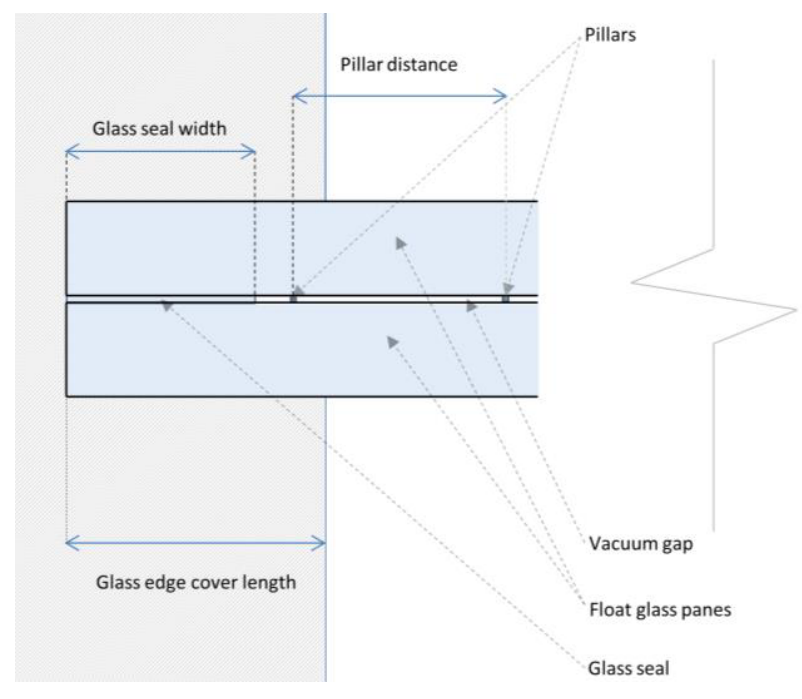

Fig. 1. Typical components of vacuum glass products and terminology used for windows equipped with vacuum glass.

In the following sections, the above-mentioned research questions are addressed mainly based on simulation efforts conducted in the projects MOTIVE [2], FIVA [3] and VAMOS [4]. Numeric thermal bridge simulation has been deployed to assess the performance of the transparent components with vacuum glass. In a previous publication [5], the principle question, if pillars should be considered in thermal simulation was explored. Thereby, it could be shown that 2D numeric thermal bridge simulations that ignore the pillars yield results that are sufficiently close to 3D simulations that consider the pillars. Thus, the outcomes of the following sections are mainly based on $2 \mathrm{D}$ simulations.

\section{General assumptions for simulations}

The numeric thermal bridge simulation tool AnTherm [6] was selected for the simulation efforts. To be able to perform the simulations, a set of input data is required. Aside from the geometry, such input data includes the thermal conductivities of the used materials, the thermal surface resistance values, and the boundary conditions of the adjacent spaces (temperatures inside, outside, interstitial spaces). Table 1 illustrates the used input data information.

\section{Retrofit of existing windows with vacuum glass products.}

The implementation of vacuum glass in existing, historically relevant windows has been explored since 2014 [9]. Historically relevant buildings in Austria often feature casement windows, which consist of two independently operable (one inner and one outer layer), separated by an interstitial air layer of about $30 \mathrm{~cm}$. The opening directions and construction details of such windows can be diverse, as illustrated in Figure 2.
Table 1. Simulation input data [7], [8].

\begin{tabular}{lc} 
Material & $\lambda\left[\mathrm{W} . \mathrm{m}^{-1} . \mathrm{K}^{-1}\right]$ \\
\hline Aluminium & 200 \\
\hline Compact Foam & 0.031 \\
\hline Glass & 1 \\
\hline Masonry & 0.45 \\
\hline Plaster & 0.7 \\
\hline Purenit & 0.096 \\
\hline Seal & 0.3 \\
\hline Seal encapsulate & 0.04 \\
\hline Silicone & 0.35 \\
\hline Steel & 60 \\
\hline Wood & 0.13 \\
\hline Encapsulate air & 0.5555 \\
\hline Vacuum & 0.00000975 \\
\hline Boundary conditions & $\mathbf{R}_{\mathbf{s}(\mathbf{H}, \mathbf{T})}\left[\mathrm{m}^{2} . \mathrm{K} . \mathrm{W} .^{-1}\right]$ \\
\hline Inside, $+20{ }^{\circ} \mathrm{C}$ & 0.25 \\
\hline Outside, $-10^{\circ} \mathrm{C} /-15 \mathrm{C}$ & 0.04 \\
\hline
\end{tabular}
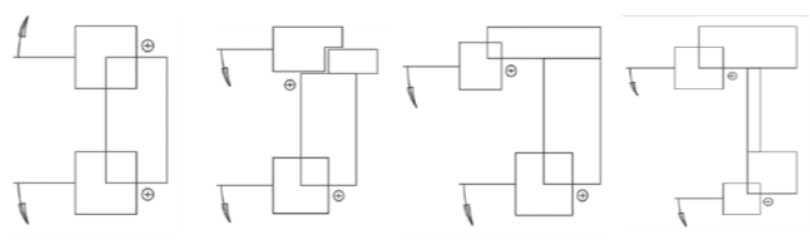

Fig. 2. Operation schemes of different casement windows.

Both layers (window wings) are typically constructed with float glass (thickness of 4 to $8 \mathrm{~mm}$ ). Retrofit measures that implement insulation glass (e.g. double glazing) for one of the window layers regularly are applied to the inner layer. This is often performed to keep the most air-tight layers close to the inside of the building. As such, the inner layer is equipped with insulation glass and sealing, while the outer layer is often kept as it is.

Certain issues must be addressed, if vacuum glass is applied instead of insulation glass: One the one hand, the application of the vacuum glass to the inner layer severely reduces the temperature in the interstitial space of the window in comparison to the original state (or even in case of retrofit with insulation glass). In extreme situation, icing of the outer glass layer might occur, reducing the transparency of the window. On the other hand, the application of the vacuum glass to the outer layer is met with scepticism by both practitioners and building physics experts. This is due to condensation risk issues that arise if the most diffusion resistant layer is situated at the outside. 


\subsection{Simulation-based assessment of casement windows}

We deployed numeric thermal bridge simulation for assessment of different scenarios of vacuum-glass application in casement windows. These scenarios are (i) original state, (ii) improvement of the inner layer with vacuum glass; (iii) improvement of the outer layer with vacuum glass. Thereby, one important aspect is the determination of an average temperature in the interstitial space, which is required as input information for the simulation environment. To determine such a temperature, we assumed that the - und steady-state boundary conditions - heat flow through the inner layer and outer layer should be equal:

$$
\begin{gathered}
\dot{Q_{l \rightarrow l s}}=L_{2 D, i \rightarrow i s} \times\left(\theta_{i}-\theta_{i s}\right)(1) \\
\dot{Q_{i s \rightarrow e}}=L_{2 D, i s \rightarrow e} \times\left(\theta_{i s}-\theta_{e}\right) \\
Q_{i \rightarrow l s}^{\cdot}=Q_{i s \rightarrow e}^{\cdot} \\
L_{2 D, i \rightarrow i s} \times\left(\theta_{i}-\theta_{i s}\right)=L_{2 D, i s \rightarrow e} \times\left(\theta_{i s}-\theta_{e}\right)
\end{gathered}
$$

Thereby, $Q_{l \rightarrow l s}$ denotes the heat flow from inside to the interstitial space $\left[\mathrm{W} . \mathrm{m}^{-2}\right], Q_{l s \rightarrow e}$ denotes the heat flow from interstitial space to external space $\left[\mathrm{W} \cdot \mathrm{m}^{-2}\right], L_{2 D, i \rightarrow i s}$ denotes the thermal coupling coefficient from inside to the interstitial space $\left[W \cdot m^{-1} \cdot K^{-1}\right], L_{2 D, i s \rightarrow e}$ denotes the thermal coupling coefficient from interstitial space to the external space $\left[W \cdot m^{-1} \cdot K^{-1}\right], \theta_{i}$ denotes the temperature of the indoor space $\left[{ }^{\circ} \mathrm{C}\right], \theta_{i s}$ denotes the temperature of the interstitial space $\left[{ }^{\circ} \mathrm{C}\right]$, and $\theta_{e}$ denotes the external temperature $\left[{ }^{\circ} \mathrm{C}\right]$. The interstitial space temperature $\theta_{\text {is }}$ remains the only unknown in this set of equations. Based on this assumption, the interstitial temperatures for the three different cases could be estimated. Thereby, an inside temperature of $20^{\circ} \mathrm{C}$ and an exterior temperature of $-15{ }^{\circ} \mathrm{C}$ were assumed.

Table 1. Interstitial space temperature of three assessed scenarios

\begin{tabular}{|l|c|}
\hline Scenario & Temperature \\
\hline (i) original state & $-1.18^{\circ} \mathrm{C}$ \\
\hline $\begin{array}{l}\text { (ii) improvement of the inner layer with } \\
\text { vacuum glass }\end{array}$ & $-6.52{ }^{\circ} \mathrm{C}$ \\
\hline $\begin{array}{l}\text { (iii) improvement of the outer layer with } \\
\text { vacuum glass }\end{array}$ & $3.26^{\circ} \mathrm{C}$ \\
\hline
\end{tabular}

\subsection{Results based on both simulations and mock-up study}

Figure 3 illustrates a casement window mock-up, which was built during the VIG-SYS-RENO project [9] for thermal testing in a hot-box-set up. The mock-up could be turned by $180^{\circ}$, so that both an application of the vacuum to the inside layer and to the outside layer could be emulated. Given the icing of the outer layer with the vacuum glass applied to the inside, these tests pointed to a clear preference for the application to the outer shell. Further details are entailed in [9].

However, in this context, recent considerations together with practitioners' feedback pose a number of related arguments: The preference for the inner or the outer layer may be strongly affected by the surrounding construction. If - for instance - a highly transmitting wall construction or cladding (e.g., made of stone) can be found in the window construction, the application on the inner side may yield better results. If the encompassing construction (window/wall joint) provides a certain insulation effect, the application to the outer shell can provide higher temperatures in both the interstitial space and along the surfaces.

Table 2 provides a comparison of false-colour images of all three scenarios. While the coldest point temperatures do not show significant differences, the general surface temperature along the outer layer is best in the case with vacuum glass in the outer layer. Figure 4 provides information about how to read the surface profile temperatures, while Figure 5 illustrates the surface temperature profiles along the inside and interstitial spaces for all three scenarios. Generally speaking, the application of vacuum glass on the inner layer results in rather high temperatures along the glass, while the coldest points do not show large differences in position and/or temperature.

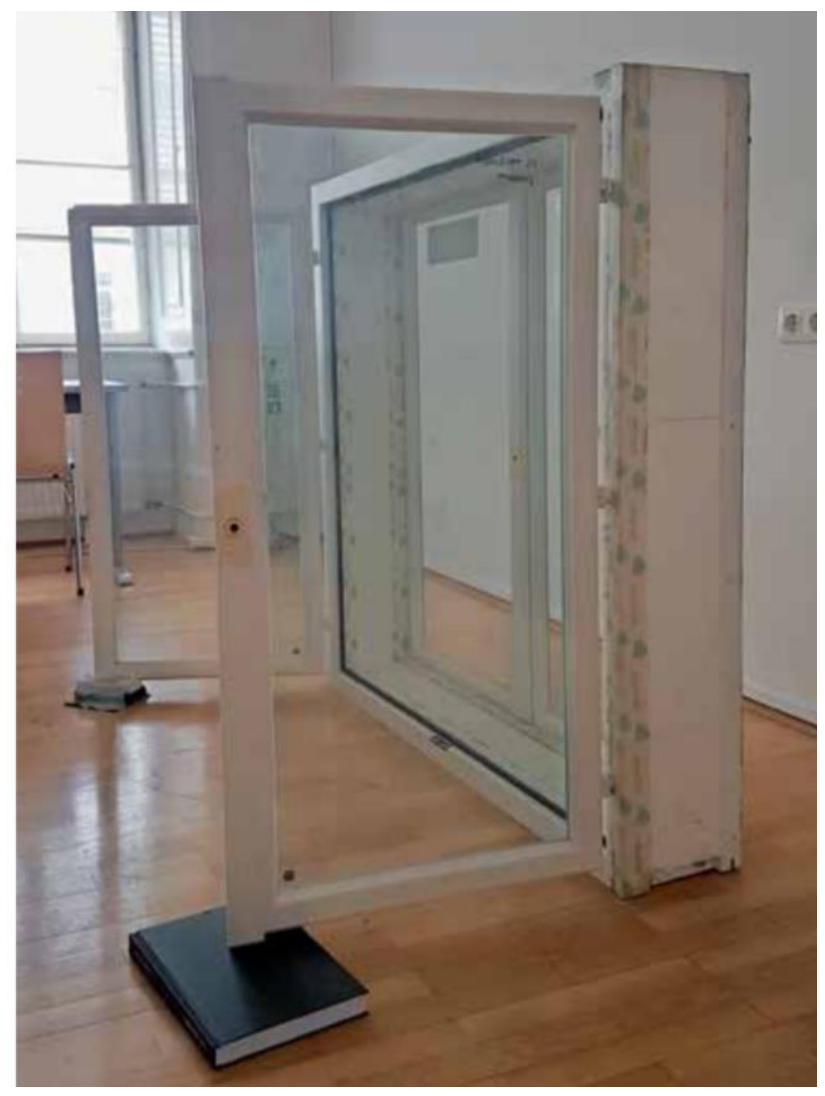

Fig. 3. Casement window mock-up. 
Table 2. Results for all three scenarios.

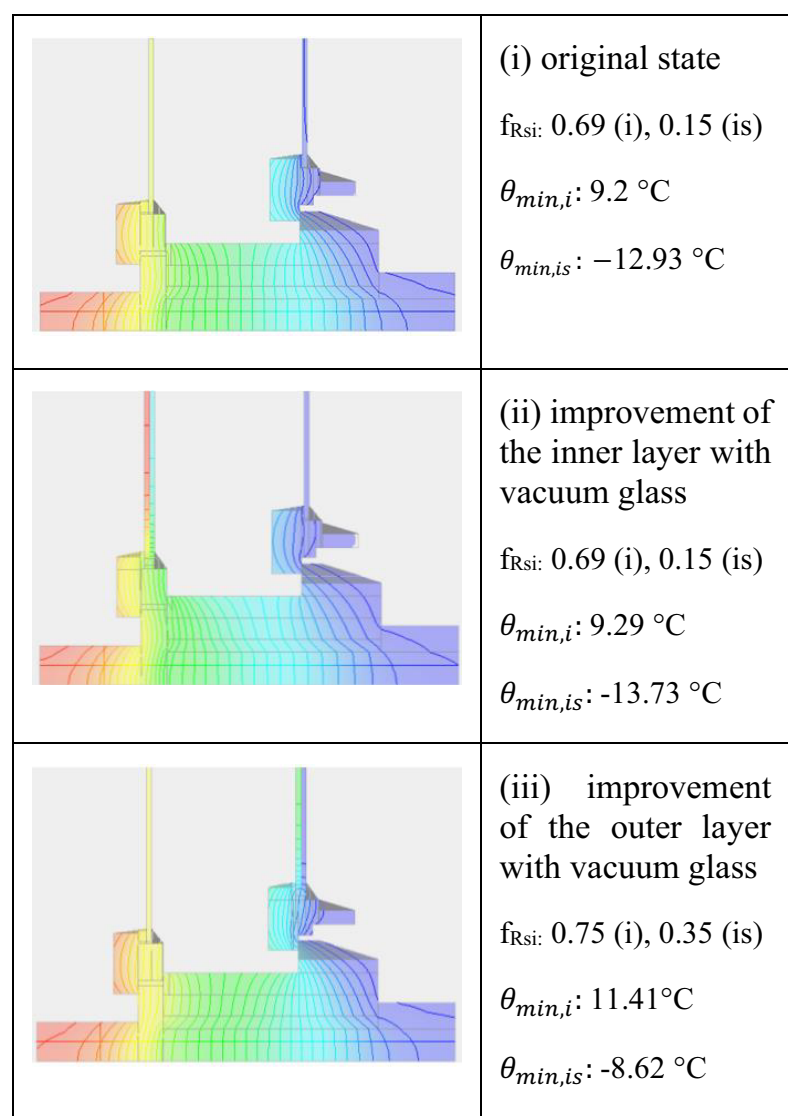

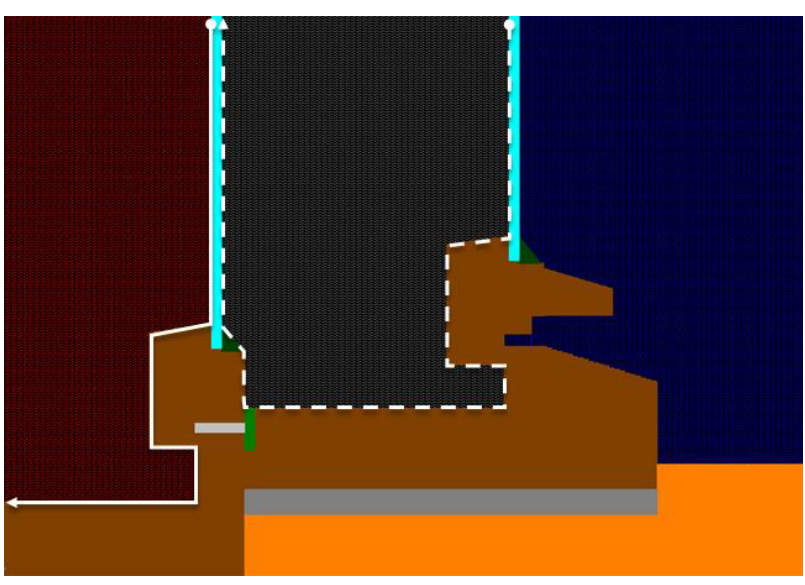

Fig. 4. Surface temperature profile routes along the inside (full line) and interstitial spaces (dashed line).

However, vacuum glass on the inner layer results in the by far lowest surface temperatures in the interstitial space. Thus, this application results in an increased risk of icing on the inner surface of the outer window layer.

The application of the vacuum glass in the outer wing provides a slight surface temperature improvement in comparison to the float glass original, but features the highest temperatures along the interstitial space surface. As such - to avoid icing - this version can be considered as favourable.

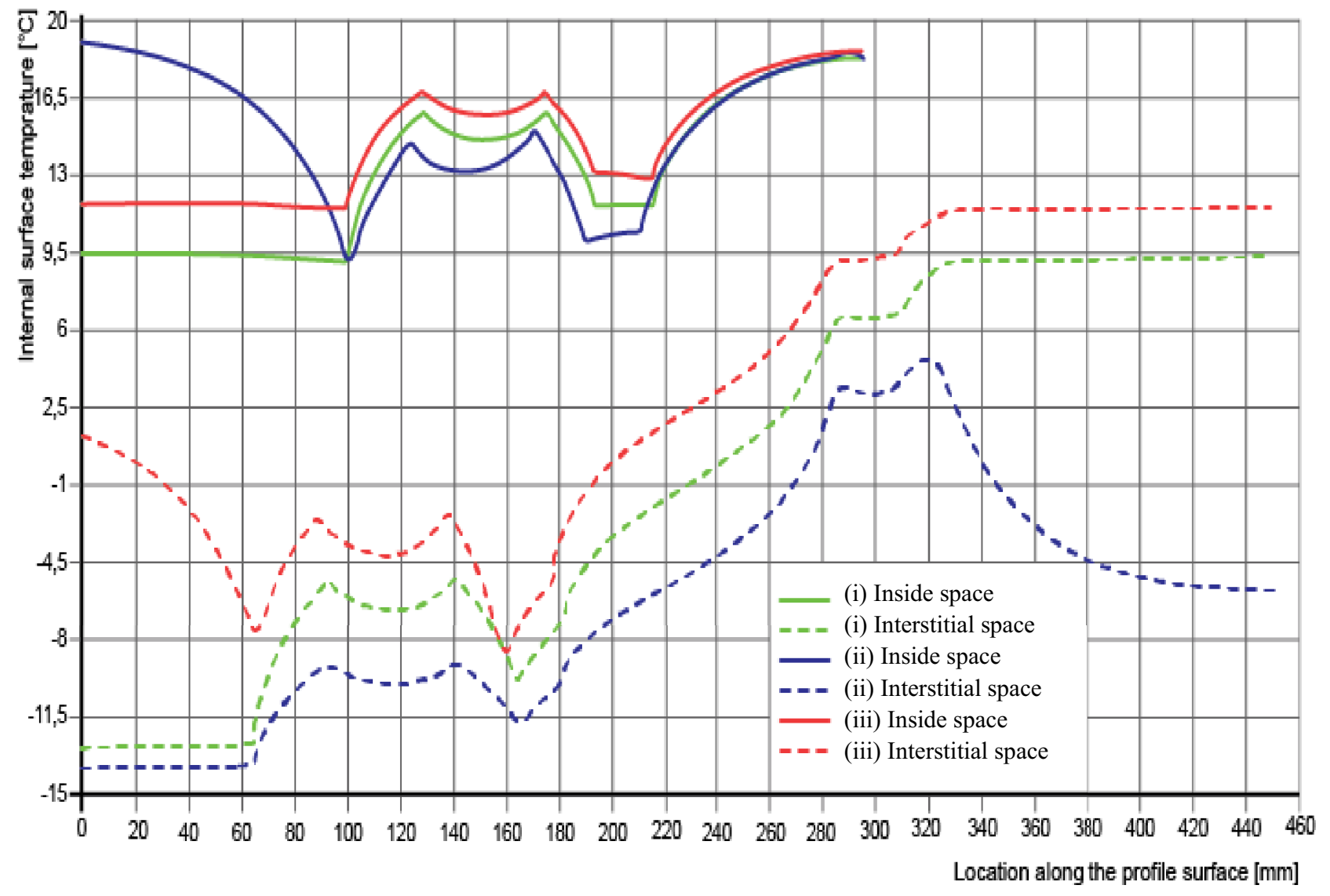

Fig. 5. Computed surface temperature profiles along the inside and interstitial spaces for all three scenarios (full line... inside space; dashed line... interstitial space). 


\section{Design of new windows with vacuum glass}

In contrast to the implementation of vacuum glass in existing window construction, the construction of new windows can be tailored towards the specifics of vacuum glass. Furthermore, this can potentially advance the way windows are constructed in central Europe.

Within the research project FIVA [3], four innovative window designs were developed, which were tailored according to the necessities of vacuum glass products. These are illustrated in Table 2. In iterative optimization processes, these four types were improved with regard to thermal performance and construction. Mock-ups of these four types were constructed in parallel (see Figure 6).

\subsection{Simulation-based performance results}

Table 3 illustrates the $f_{\text {Rsi-values }}$ and coldest-point temperatures of the different construction designs. Note that - with the exception of the turn window opening to inside - the $\mathrm{f}_{\mathrm{Rsi}}$-values could be optimised close to the threshold values suggested for opaque constructions [10]. All constructions feature a glass edge cover length of at least $40 \mathrm{~mm}$.
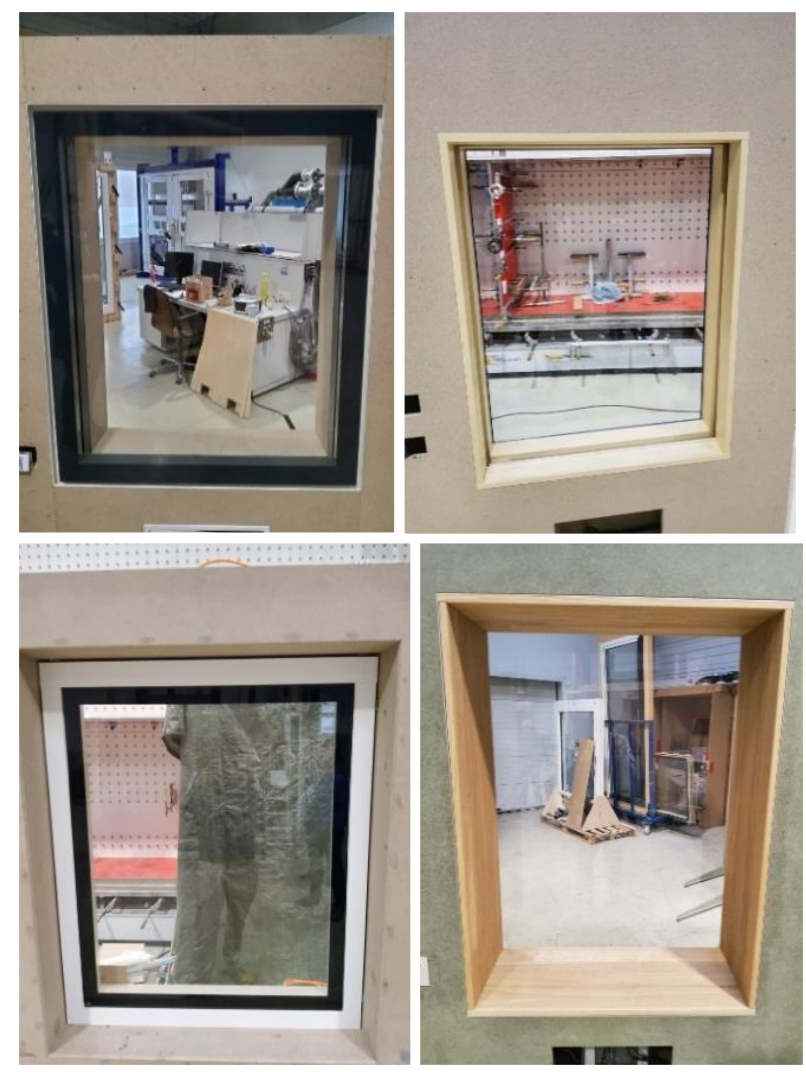

Fig. 6. Built mock-ups of the four types: turn window opening to inside (upper left), turn window opening to outside (upper right), swing window (lower left), sliding window (lower right).
The turn window to the inside, however, provides a rather low fRsi-value, which is the result of the larger surface area to the outside. The turn window opening to the outside - in contrast - shows better results regarding the fRsi-value, due to smaller exposed external area and the insulation effect of the window situated on the outer perimeter of the construction. The Swing window provides similar results. In this case the actual performance around the turning point has to be extensively examined in future efforts.

The sliding window features the by-far best performance, regarding the minimum surface temperatures. This is due to the extensive use of seals in the construction, which provides insulating air pockets within the construction. The turn window to the inside, however, provides a rather low $\mathrm{f}_{\mathrm{Rsi}}$-value, which is caused by the larger surface area to the outside.

Figure 7 illustrates the thermal performance of the lower building construction joint / detail (Window to wall construction detail) of each of the constructions at a current development state.

Table 3. Different designs of new windows equipped with vacuum glass.

\begin{tabular}{|c|c|c|c|}
\hline Design & Operation Schematics & $\begin{array}{l}\mathbf{f}_{\text {Rsi }} \\
{[-]}\end{array}$ & $\begin{array}{c}\boldsymbol{\theta}_{\min , i} \\
{\left[{ }^{\circ} \mathbf{C}\right]}\end{array}$ \\
\hline $\begin{array}{l}\text { Turn } \\
\text { window } \\
\text { opening } \\
\text { to inside }\end{array}$ & & 0.49 & 4.74 \\
\hline $\begin{array}{l}\text { Turn } \\
\text { window } \\
\text { opening } \\
\text { to outside }\end{array}$ & & 0.67 & 10.05 \\
\hline $\begin{array}{l}\text { Swing } \\
\text { window }\end{array}$ & & 0.65 & 9.49 \\
\hline $\begin{array}{l}\text { Sliding } \\
\text { window }\end{array}$ & & 0.76 & 12.76 \\
\hline
\end{tabular}




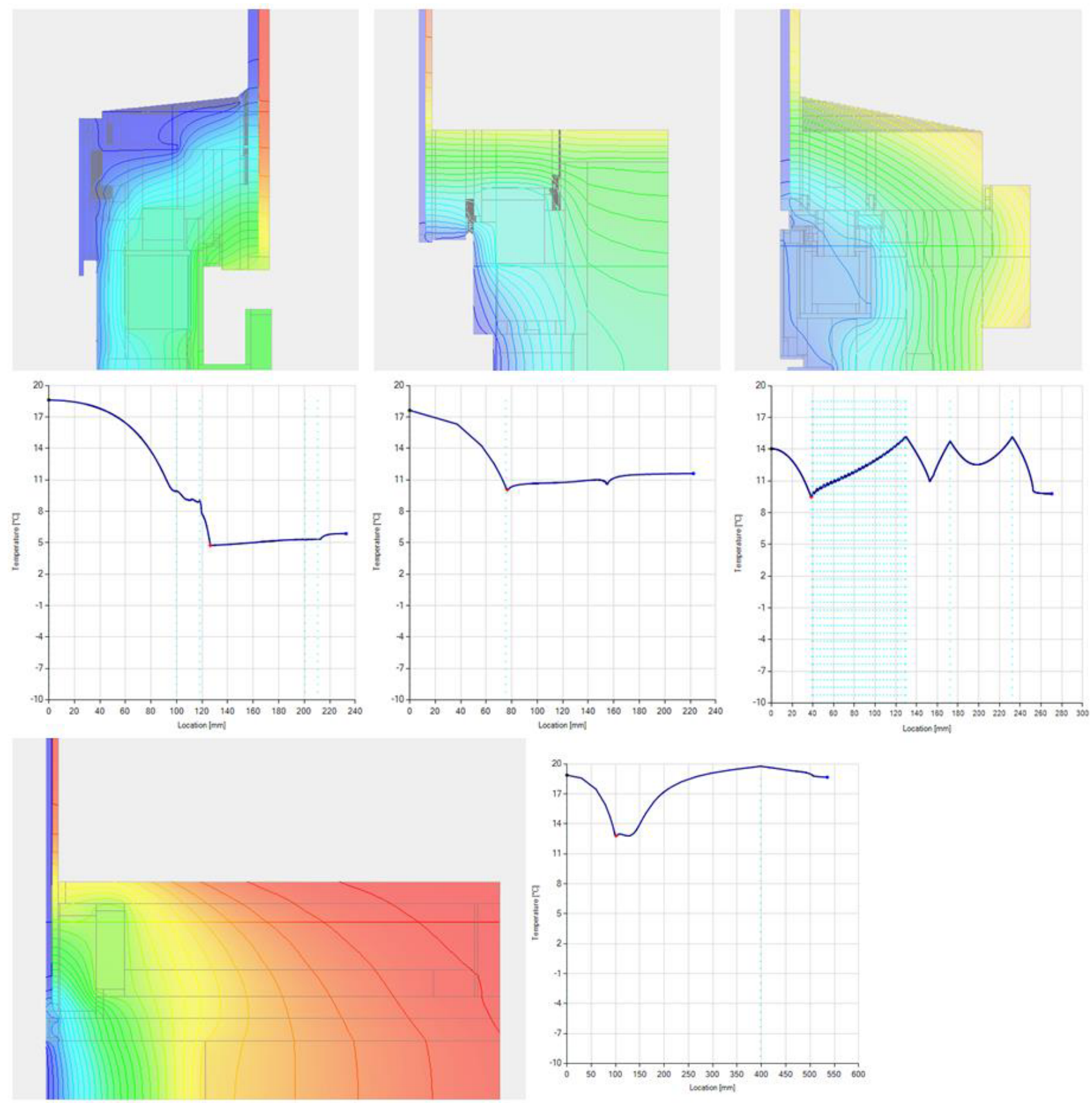

Fig. 7. False-colour image and surface temperature profiles along the inside spaces of the lower construction detail of the four types: turn window opening to inside (upper left), turn window opening to outside (upper center), swing window (upper right), sliding window (lower part).

\subsection{Preliminary calibration results}

For one of the four types (Turn window opening to the inside), preliminary calibration runs are being conducted based on measurements. Thereby, the measured performance of the window showed higher surface temperature results than expected from the simulation results. In one of the earlier calibration runs, the assumed inside $\mathrm{R}_{\mathrm{si}}$ value was changed from 0.25 to $0.13 \mathrm{~m}^{2} \mathrm{~K} . \mathrm{W}^{-1}$, which represents the regular $\mathrm{R}_{\mathrm{si}}$ suggested by EN ISO
6946 [10]. However, the later value has been often suggested to be too low given the hindered convection in case of non-planar details (e.g., construction edges and corners). While originally the differences of the lowest surface temperature (between simulation and measurement) were up to 8 kelvin, the modification of the $\mathrm{R}_{\mathrm{si}}$-value reduced this difference to less than 3 kelvin. Note that the reliability of these findings needs to be examined in a more detailed and in-depth manner in the course of future studies. 


\section{Implementation of vacuum glass products in typical post-and-beam facades}

We assessed the performance of vacuum glass products in typical post-and-beam construction profiles [11], one made of timber, the other one made of steel profiles. Thereby, different implementation options were tested. These are described in Table 4. Figure 9 illustrates the performance of the different applications in view of the Key Performance Indicator $\mathrm{f}_{\text {Rsi }}$. Thereby, results are compared for 2D simulation (2D), 3D simulation (3DL), and 3D-simulation including connective elements, such as screws (3DL_S). In most cases the application of the vacuum glass shows a better coldest-point performance than the double glazing glass (ISO). However, depending on the used post/beam construction, and the consideration of the screw, the enhancement scope was different. In few cases, even the condensation criteria for non-transparent constructions could be fulfilled ( $f_{\text {Rsi }}$ of 0.69 ).

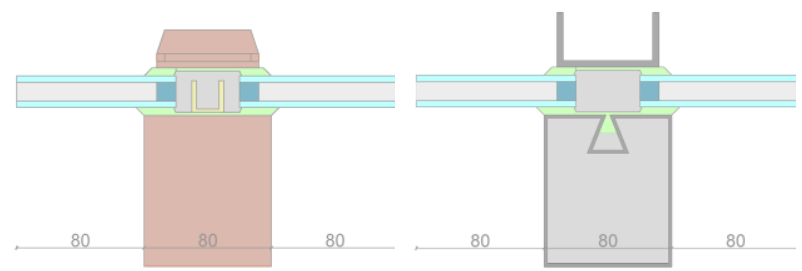

Fig. 8. Original timber (left) and steel construction post- \& beam façade details as used in this study (ISO application form).

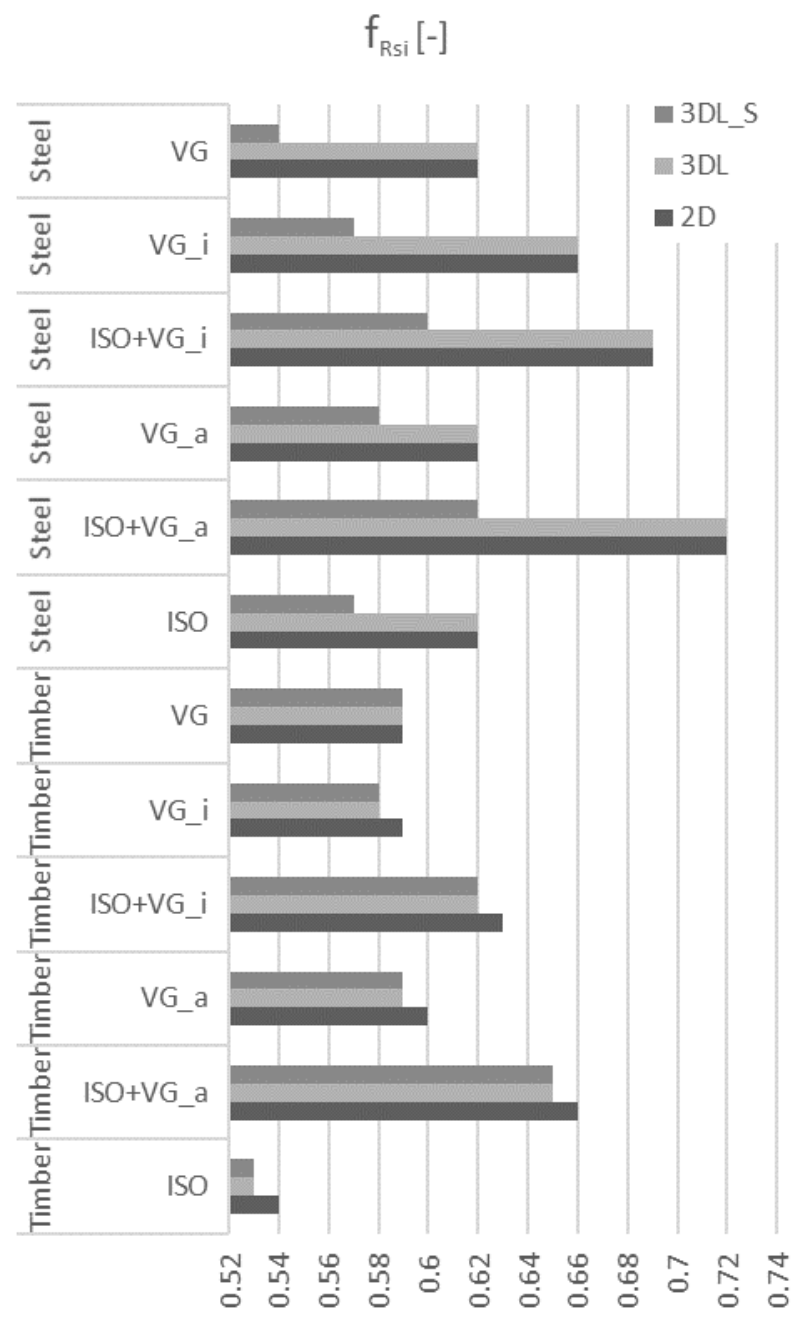

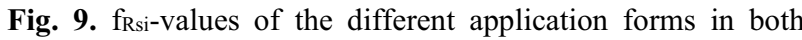
timber and steel post - and beam façade construction (derived from simulation).

Table 4. Different application forms of vacuum glass in post/beam facades.

\begin{tabular}{|c|c|c|}
\hline Scenario & Description & Illustration \\
\hline ISO & $\begin{array}{l}\text { Façade construction equipped with regular insulation glass (two glass panes, Argon-filled } \\
\text { interstitial gap; } 4-12-4 \text { ) }\end{array}$ & \\
\hline $\mathrm{ISO}+\mathrm{VG}_{-} \mathrm{a}$ & $\begin{array}{l}\text { Based on ISO (same profile), but exchange of exterior glass against insulation glass } \\
\text { (vacuum glass pane, argon-filled interstitial gap, } 8.15-7.85-4 \text { ) }\end{array}$ & 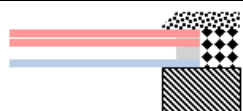 \\
\hline VG_a & $\begin{array}{l}\text { Similar to ISO+VGa, but reduced to the vacuum glass pane (no additional insulation } \\
\text { glass layer); Seal-prolongation on the inside }\end{array}$ & \\
\hline $\mathrm{ISO}+$ VG_i & $\begin{array}{l}\text { Based on ISO (same profile), but exchange of interior glass against insulation glass } \\
\text { (vacuum glass pane, argon-filled interstitial gap, 4-7.85-8.15) }\end{array}$ & \\
\hline VG_i & $\begin{array}{l}\text { Similar to ISO+VGi, but reduced to the vacuum glass pane (no additional insulation glass } \\
\text { layer); Seal-prolongation on the outside }\end{array}$ & \\
\hline VG & Reduced profile; profile was adapted to the vacuum glass thickness $(8.15 \mathrm{~mm})$ & $=$ \\
\hline
\end{tabular}




\section{Conclusion}

The present contribution discussed the implementation of vacuum glass products in different new and existing window and façade constructions. Based on the results of the past and ongoing research projects, the research questions can be answered as follows:

Question 1: Vacuum glass can provide a thermal enhancement of existing casement windows. Thereby, the improvement of the general performance in view of the $\mathrm{U}$-Value reduction can be achieved, no matter if vacuum glass is applied to the inner or the outer layer. However, the detailing, temperatures along the profiles, and coldest point temperatures need a careful consideration on a caseby-case base.

Question 2: The presented designs all considered the edge seal as the weak spot of the vacuum glass. To mitigate this thermal bridge along the glass edge corner, either additional sealing materials was implemented, or the glass edge were wrapped by framing material. Key performance indicators of the majority of the considered designs can be shown to come close to the thresholds suggested for opaque constructions.

Question 3: The simulation-based change from double glazing to different application forms of vacuum glass showed that the performance of the post-and-beam facades could be improved even without changing the principle construction form. However, should vacuum glass products become mainstream, post- and beam constructions might be reconstructed along the lines of the windows presented when addressing question 2 .

The treatment presented in this paper is of course limited in that it is still mainly relies on numeric thermal bridge simulation. Moreover, the underlying simulation are in this case steady-state and address only conductive heat transfer in detail (convective heat transfer is considered only in a highly simplified fashion, and radiative heat transfer is not considered). Intended future efforts include the augmentation of simulation domain in terms of transient regime and inclusion of convective and radiative heat transfer phenomena in detail. Moreover, efforts toward experimental tests based on construction mock-ups and in-situ implementation are expected to generate data toward actual performance evaluation and simulation model calibration.

The past and ongoing research efforts described in this paper have been funded by the Austrian Research Promotion Agency (FFG). Funded projects include in particular: VIG-SYS-RENO (2014-2015), Pr.No. 845225 (a general assessment of Vacuum glazing products and their principle utility for existing windows); MOTIVE (2016-2017; Pr.No.854690); FIVA (20182020) Pr. No. 867352 (development of new windows with implemented vacuum glass), and VAMOS (2019-2021), Pr.No.: 878272 (realization/retrofit and monitoring of historically meaningful windows with vacuum glass). Moreover, the research and development efforts have been supported by stakeholders of the window constructing industries, including AGC, ieb Eisele, Gaulhofer, Internorm, Katzbeck, Maco, Prohaska, Schaden, Svoboda, Wick, Winkler, and Zoller.

\section{References}

1. A. Zoller (1924): DE387655C - Hohle Glasscheibe. Google Patents. With assistance of Dipl-Ing Alfred Zoeller. https://patents.google.com/patent/DE387655C/de, updated on 10/29/1913 (last checked: Dec 2019)

2. MOTIVE project, see: https://nachhaltigwirtschaften.at/de/sdz/publikationen/schri ftenreihe-2018-24-motive.php (last checked: Dec 2019).

3. FIVA project, see: https://nachhaltigwirtschaften.at/de/sdz/projekte/fiva.php (last checked: Dec 2019).

4. VAMOS project, see: https://nachhaltigwirtschaften.at/de/sdz/projekte/vamos.php (last checked: Dec 2019).

5. U. Pont, A. Mahdavi, A comparison of the performance of two- and three-dimensional thermal bridge assessment for typical construction joints, Building Simulation Applications Proceedings, Paper ID 75 (2017)

6. AnTherm. www.antherm.eu (last checked: Dec 2019).

7. ISO 10077-2:2017: Thermal performance of windows, doors and shutters - Calculation of thermal transmittance - Part 2: Numerical method for frames (ISO 100772:2017)

8. ÖNORM B 8110-2: Thermal insulation in building construction - Part 2: Water vapour diffusion and protection against condensation. 2003-07-01, Austrian Standardization Institute.

9. VIG SYS-RENO project, see: https://nachhaltigwirtschaften.at/de/sdz/projekte/vig-sysreno.php (last checked: Dec 2019).

10. ISO 6946:2017: Building components and building elements - Thermal resistance and thermal transmittance - Calculation methods (ISO 6946:2017)

11. M. Wölzl, U. Pont, P. Schober, A. Mahdavi, Simulationbased performance comparison of Facade Constructions: Vacuum glazing versus common insulation glass, Talk: EnviBUILD2019 - Buildings and Environment International Conference, Bratislava, Slovake; "Book of Abstracts of the 14th enviBUILD 2019 (2019) 